\title{
STUDIES OF PULMONARY CAPACITY AND MIXING WITH THE NITROGEN METER ${ }^{1}$
}

\author{
By WILliaM A. WOLFE AND LOREN D. CARLSON \\ (From the Department of Physiology and Biophysics, School of Medicine, University of \\ Washington, Seattle, Wash.)
}

(Submitted for publication June 12, 1950; accepted, September 5, 1950)

\section{INTRODUCTION}

Residual air, when related to total lung volume, establishes the presence and degree of pulmonary hyperinflation (emphysema). When continuous gas analysis is used to measure residual air, the rate of gas dilution or "clearing" also depicts the process of gas mixture within the lung. Unfortunately, the special equipment and technical skill required have limited clinical interest in quantitative pulmonary studies.

The closed circuit method has been criticized by Lassen and associates (1) because of the continual nitrogen concentration within the system ("oxygen storage" or "nitrogen lag"). Although the closed circuit method appears to give somewhat higher values than open circuit (2) or constant volume (3-5) methods in normal individuals, such differences are not as apparent in pathological subjects where faulty mixing and other factors cause poor testing reproducibility in all methods. Since clinical adaptability rather than maximum accuracy was the goal in this study, a closed circuit method was adopted.

The equipment and technique were simplified to make tests of total lung capacity and intrapulmonic mixing more suitable for clinical use. The essential features of this method are continuous electronic gas analysis from an unaltered commercial metabolism machine, applied to a modification of the Christie closed circuit technique (6). A new mixing index, a measure of ventilatory efficiency, has been derived from the data obtained in this study.

Cournand and colleagues (7), described an "index of intrapulmonary mixing" in their recent studies on pulmonary insufficiency using an open circuit method. Their index is simply the per cent of nitrogen in the alveoli at the end of seven

1 This study was aided in part by funds from $H$. E. Curry Co., Seattle, Washington, and A. F. Contract $33 / 038 /-422$. minutes of oxygen breathing. This arbitrary period is adequate for most subjects to clear all but 2.5 per cent nitrogen from their lungs. However, as the authors pointed out, the final nitrogen concentration in a subject with a high respiratory rate (large minute volume) and a poorly mixing lung might be the same as that in a normal subject with a much lower minute volume.

Boothby and co-workers (8) used the nitrogen meter with a closed circuit method to test efficiency of tidal breathing. The test was the time necessary to clear nitrogen from the lungs, which varied from two to three and one-half minutes in normal individuals. Their test also does not take into account differences in minute volume. This fallacy was avoided in devising our pulmonary mixing index because graphical recording of the clearing process permits judging of the time and number of respirations required to reach the end point in the process. Efficiency is related to ventilation and lung size, rather than to time.

\section{METHOD}

The complete apparatus is shown in Figure $1 .^{2}$

Meter. The analyzing device was the nitrogen meter developed by Lilly and Anderson $(9,10)$. The delay between the sampling needle and the analyzer was 1.8 seconds, and the time to reach peak value on the tracing was an additional 2.8 seconds, mainly due to mixing in the lead-in system rather than to instrumental delay. A ceramic orifice admitted $50 \mathrm{cc}$. of sample gas a minute at the operating pressure of $60 \mathrm{~mm}$. of Apiezon B oil. The lead-in plastic tubing to the orifice was 0.034 inch in bore and 45 inches long. The distal end of the tubing was attached to a No. 20 hypodermic needle, and the proximal end affixed to a $100 \mathrm{cc}$. drying chamber containing 8 mesh anhydrous calcium sulfate. The drying chamber, in turn, led directly into the ceramic orifice mounted on the meter. Recording was through a DC amplifier (BL-913, Brush Development Company) to a direct-writing oscillograph (BL-202, Brush Development Company) which gives a maximum pen swing of $40 \mathrm{~mm}$.

2 The apparatus was described in a preliminary abstract: Federation Proc., 1948, 7, 18. 


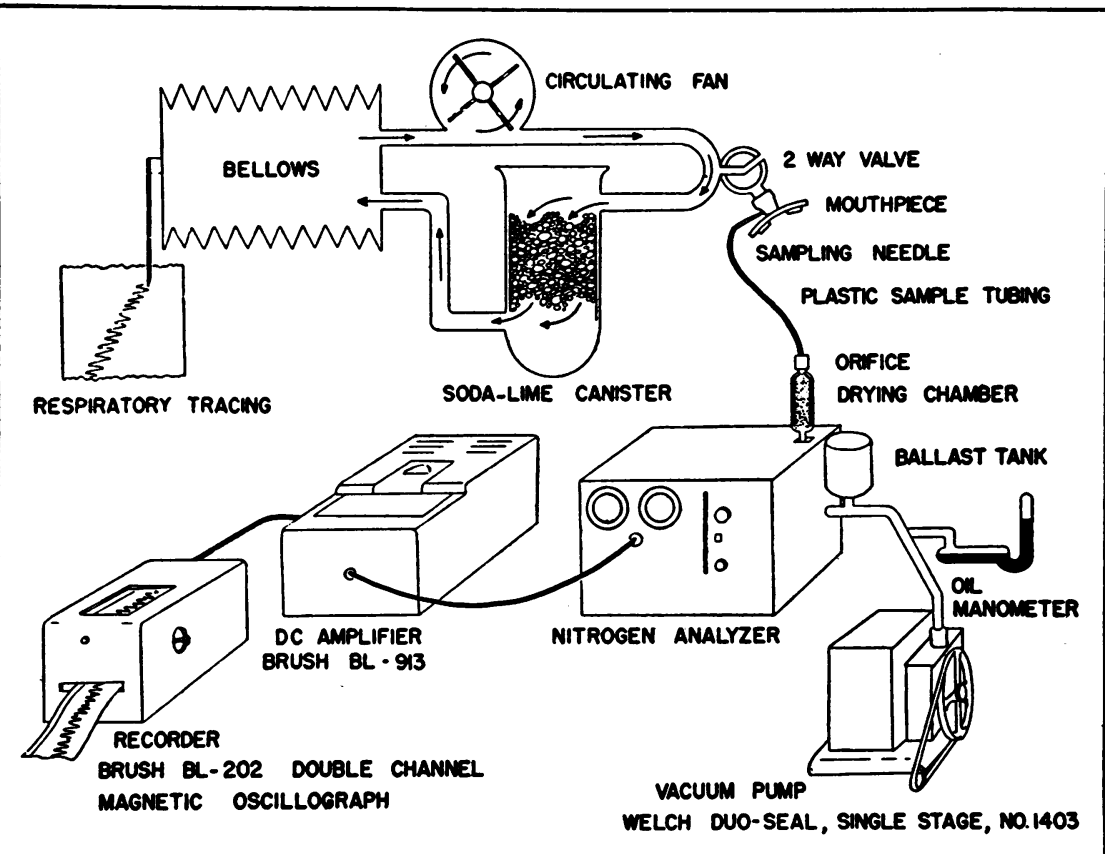

Fig. 1. The Metabolism Machine (Schematic) and Nitrogen Analyzer with Recording Apparatus Used for Determining Functional Residual Air ANd Mixing Efficiency

Spirometer. The spirometer was a standard waterless BMR machine, the Sanborn Metabulator, used with a twoway breathing valve assembly (241-358, Sanborn Company) at the mouthpiece. The blower circulates the internal gas through the tubing at a rate of 25 liters/ minute. A single tidal breath is almost completely mixed with machine oxygen in eight seconds. The tendency of the machine to heat during testing was countered by playing a fan on the blower assembly and bellows.

Total internal volume of the machine at a point near complete expansion of the bellows $(37 \mathrm{~mm}$. from the top of the recording paper) was determined by gas dilution with Scholander and Haldane-Henderson gas analyses. The total volume calculated for this machine is 10.24 liters; subtracting the volume of the breathing valve assembly gives the final figure 10.22 liters.

Before the test, the two escape holes in the machine valve assembly were corked and the "Fill" valve adjusted so that streams of oxygen issued from both the open mouthpiece valve and the escape valve in the bellows, when the machine was flushed with tank oxygen at 20 liters/minute. With the blower in motion, ten minutes of flushing regularly brought the spirometer nitrogen within 0.1 per cent of that of tank oxygen ( 0.4 per cent nitrogen). Late in this study, the analysis for the initial spirometer impurity (a result of nitrogen in the tank oxygen and of flushing imperfection) was discontinued, and a value of 0.2 per cent assumed. The impurity of the tank oxygen used for most of this study was unusually low ( 0.1 per cent nitrogen).
Testing procedure. The subjects rested 20-30 minutes before the test, but otherwise were not in a basal state. The testing position was supine and hands at the side. The spirometer, previously tested for leaks and flushed, was adjusted to the standard volume and the mouthpiece (assembly switched to room air) was fitted to the subject. The nitrogen meter record was standardized with a stream of oxygen to insure that the maximum scale was being utilized. The meter sampling needle was then thrust through the mouthpiece wall to the middle of the mouthpiece stem. At the end of a tidal expiration, the subject was switched into the spirometer circuit and the test continued until the nitrogen concentration tracing became a straight line-i.e., until inspiratory and expiratory nitrogen concentrations were visually equal. After maximal expiration, the sampling needle was immediately withdrawn for several standardizing exposures to a stream of pure oxygen from an oxygen tank tubing. Finally, the subject was instructed to produce two more maximal expirations, each separated by tidal breathing, and three maximal inspirations, also separated by tidal breathing.

Calculation. When the lungs rebreathe into a spirometer containing a known volume of oxygen until the concentrations of nitrogen in the lungs and in the spirometer are virtually equal ("equilibration"), the lung volume can be calculated from the following statement:

$$
\text { Lung Volume } \times \mathrm{fN}=\left(\text { Lung Volume }+\mathrm{V}_{\mathrm{s}}\right) \mathrm{f}^{\prime} \mathrm{N},
$$


where:

Lung Volume $=$ Functional Residual Air (FRA), if the test is begun at the end of a tidal expiration.

FRA = residual, reserve, and respiratory dead air in cc. as saturated gas at machine temperature and existing barometric pressure.

$\mathrm{fN}=$ Average intrapulmonic nitrogen fraction before the test-i.e., during air breathing. The constant figure of 0.800 is used for this value.

$\mathrm{V}_{\mathbf{1}}$ = Spirometer volume including its dead space, saturated at machine temperature and existing barometric pressure, appropriately corrected if the test is not begun exactly at the end of a normal expiration.

$f^{\prime} \mathrm{N}=$ Fraction of nitrogen in the lung and spirometer af ter equilibration.

Several corrections must be added to the above statement:

1) The initial spirometer volume actually contains about 0.4 per cent nitrogen from tank impurity and 0.1 per cent from imperfect flushing. This impurity is represented by the symbol $\mathrm{fN}_{\mathrm{i}}$ :

$$
\mathrm{FRA} \times \mathrm{fN}+\mathrm{V}_{\mathrm{f}} \mathrm{fN}_{\mathrm{i}}=\left(\mathrm{FRA}+\mathrm{V}_{\mathbf{s}}\right) \mathrm{f}^{\prime} \mathrm{N} .
$$

2) The initial and final spirometer volumes are dissimilar by the amount of oxygen lost to the patient and to the continuous sampling of the analyzer. The former value may be represented by " $\mathrm{O}_{2}$," which is saturated oxygen at machine temperature, directly measured on the spirometer tracing as the vertical distance between the initial and final respiratory resting level (expiration). The sampling loss is $\mathbf{5 0}$ multiplied by the time of the test in minutes " $t$ ":

$\mathrm{FRA} \times \mathrm{fN}+\mathrm{V}_{\mathrm{b}} \mathrm{N}_{\mathrm{i}}=\mathrm{FRA} \times \mathrm{f}^{\prime} \mathrm{N}$

$$
+\left(\mathrm{V}_{\mathrm{s}}-\mathrm{O}_{2}-50 \mathrm{t}\right) \mathrm{f}^{\prime} \mathrm{N} \text {. }
$$

3) Extraneous nitrogen from lung excretion of bodily stores is added to the circuit during the test. The nitrogen excretion value must be subtracted from the right side of the statement. Derivation of this factor:

$$
\frac{\mathrm{fN}-\mathrm{f}^{\prime} \mathrm{N}}{\mathrm{fN}}(0.387 \text { Body Wgt. in Kg. }+16)
$$

is from a seven minute nitrogen excretion formula for basal subjects $[1.82 \times$ Body Wgt. in $\mathrm{Kg} .+76$, Cournand and associates (11)], modified for the closed circuit system and non-basal resting subjects by the factors $\frac{\mathrm{fN}-\mathrm{f}^{\prime} \mathrm{N}}{0.8}$ and $\frac{320}{215}$ respectively [Darling and co-workers (12)] and expressed at a per minute rate.

Substituting the values $\mathrm{fN}=0.800$ and $\mathrm{fN}_{\mathrm{i}}=0.005$ and solving:

$$
\begin{aligned}
F R A=\frac{V_{s}\left(f^{\prime} \mathrm{N}-0.005\right)-\left(\mathrm{O}_{2}+50 t\right) f^{\prime} \mathrm{N}}{0.800-\mathrm{f}^{\prime} \mathrm{N}} \\
-\frac{0.387 \mathrm{BW}+16}{0.800} .
\end{aligned}
$$

The FRA so obtained represents gas at the condition of the test (saturated, machine temperature, existing barometric pressure) and is corrected to the equivalent volume at standard lung conditions (saturated, body temperature,
$760 \mathrm{~mm} . \mathrm{Hg}$ ). In these studies the correction factor of 1.07 embraced the usual variation of these factors. Finally, $20 \mathrm{cc}$. is subtracted to allow for the volume of the mouthpiece and breathing valve, thus eliminating an artifactual enlargement of the respiratory dead space.

Meter calibration. The nitrogen meter was calibrated throughout the studies with duplicate Haldane-Henderson analyses, performed by a dilution method on a standard apparatus which was graduated from 7.00 to 10.00 .

Warm-up periods of one hour for the amplifier and onehalf hour for the meter were allowed, to minimize drift. A constant voltage transformer prevented fluctuations from changes in line voltage. Meter readings were read as the difference between the oxygen standardization $(0$ per cent nitrogen) line and the unknown gas mixture line, corrected for variations in gain by multiplication with the fraction $\frac{\text { standard air line volume }}{\text { observed air line volume }}$

Over a one-month period the standard deviation of random meter values from the mean (curve) values was \pm 3.5 per cent of any given nitrogen concentration through the experimental range-e.g., \pm 0.7 per cent at the 20 per cent point of the calibration curve. The calibration curve was not quite linear, but for simplicity was drawn as a linear curve broken at 20 per cent and 28 per cent nitrogen.

\section{THE PULMONARY MIXING INDEX}

In measuring pulmonary mixing, emptying, or clearing of inspired gases two variables are apparent: 1 ) the size of the compartment to be cleared (FRA), and 2) the amount of ventilation necessary to effect clearing (the total ventilation to "equilibration"). The index of pulmonary mixing devised in this study involves the assumption that the clearing ventilation of normal subjects is proportionate to lung size ( $\left.\frac{\text { Clearing ventilation }}{\text { FRA }}\right)$. The reciprocal of this fraction has been adopted so that the smaller index will indicate relative inefficiency. The index is stated:

$$
\text { FRA }
$$

$\overline{\text { Total ventilation to equilibration }}$

or

FRA

Average tidal volume $X$ respiratory rate

$$
X \text { time to equilibration }
$$

The second formula illustrates the influence of (excessive) FRA size, poor mixing, and shallow respirations on mixing efficiency. Even in a single normal individual there is considerable daily variation in tidal volume-and therefore in the relative influence of the respiratory dead spaceso that absolute constancy of the index cannot be expected.

Computation of "total ventilation to equilibration" requires two steps: 1) counting all readily discernable respiratory waves on the nitrogen meter tracing; and 2) measuring the corresponding respiratory excursions on the spirometer tracing with a millimeter rule, to determine the average tidal volume. In the regular tracings of trained normal subjects, it suffices to draw envelope slope lines over the appropriate area of the spirometer tracing and measure directly the midpoint average tidal breath. In 
TABLE I

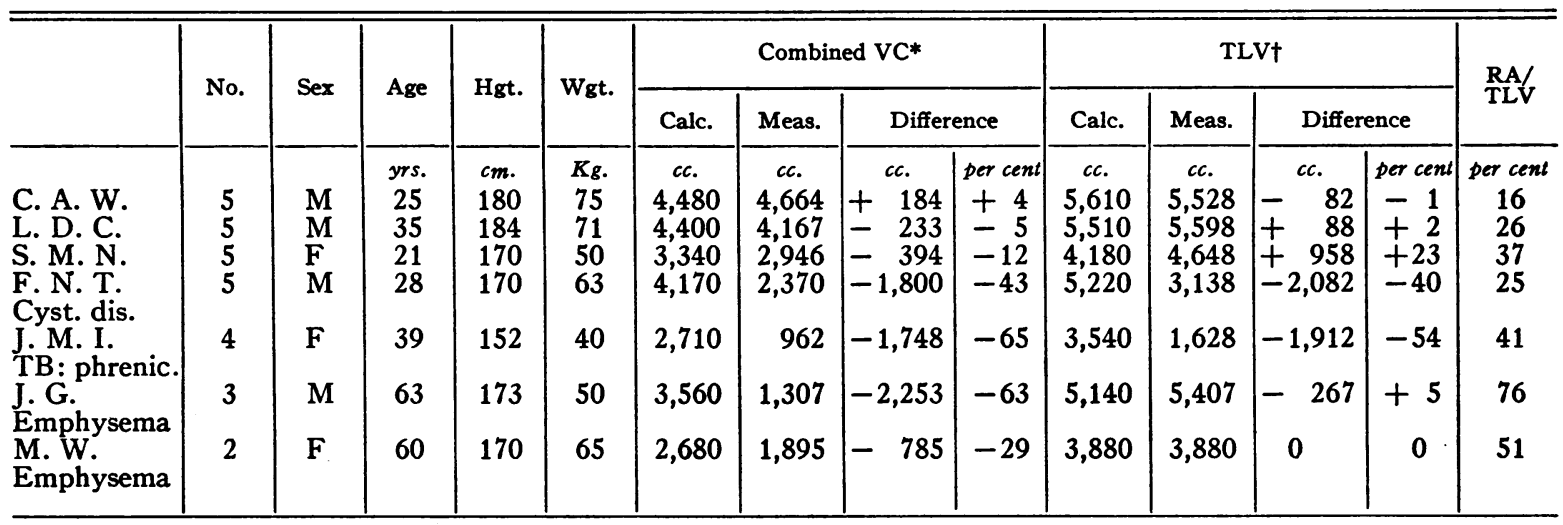

\section{Prediction Formulas}

From Baldwin (13)

$* \mathrm{VC}$ in males cc. $=27.63-(0.112 \times$ age $) \times \mathrm{Hgt} . \mathrm{cm}$.

$\mathrm{VC}$ in females cc. $=21.78-(0.101 \times$ age $) \times \mathrm{Hgt} . \mathrm{cm}$.

Modified from Baldwin (13)

$$
\begin{aligned}
\dagger T L V & \text { between 16-34 yrs. of age }= \\
\text { TLV between } 35-49 \text { yrs. of age } & =\frac{\text { Predicted VC }}{80.0} \times 100 \\
\text { TLV between } 50-69 \text { yrs. of age } & =\frac{\text { Predicted VC }}{69.2} \times 100
\end{aligned}
$$

patients with severe emphysema, however, the respiratory rate is high, and no straight slope lines can be drawn accurately. Therefore, a curved envelope is drawn and tidal breaths measured at 0.2 inch intervals.

\section{RESULTS}

The descriptive data for the three normal and four abnormal subjects in this study are listed in Table I. Baldwin and colleagues' (13) formulas of prediction for normal individuals were used except that total lung volume was derived from pre- dicted rather than measured vital capacity, since no meaningful prediction could be obtained from grossly abnormal measurements.

In Table II, the subjects are arranged in decreasing ventilatory efficiency (mixing index), the factor data being listed in the last four columns. The data for the three normals show the correlation between the index and its constituent factors. Thus, respiratory rate increases as the mixing

\begin{tabular}{|c|c|c|c|c|c|c|c|c|}
\hline Case & No. & Diagnosis & $\underset{\text { index }}{\text { Mixing }}$ & S.D. & $\begin{array}{l}\text { Minutes } \\
\text { to clear }\end{array}$ & $\begin{array}{l}\text { Resp./ } \\
\text { minute }\end{array}$ & $\begin{array}{c}\text { Tidal } \\
\text { volume }\end{array}$ & $\begin{array}{l}\text { Functional } \\
\text { residual air }\end{array}$ \\
\hline $\begin{array}{l}\text { M. N. } \\
\text { D. C. } \\
\text { A. W. } \\
\text { N. T. } \\
\text { G. } \\
\text { M. I. }\end{array}$ & $\begin{array}{l}5 \\
4 \\
4 \\
3 \\
3 \\
2 \\
4\end{array}$ & $\begin{array}{l}\text { Normal } \\
\text { Normal } \\
\text { Normal } \\
\text { Cong. cystic dis. } \\
\text { Emphysema } \\
\text { Emphysema } \\
\text { TB: phrenicectomy }\end{array}$ & $\begin{array}{l}.21 \\
.15 \\
.14 \\
.12 \\
.10 \\
.06 \\
.03\end{array}$ & $\begin{array}{l} \pm .028 \\
\pm .017 \\
\pm .011 \\
\pm .016 \\
\pm .026 \\
.0 \\
\pm .006\end{array}$ & $\begin{array}{l}1.9 \\
2.8 \\
2.0 \\
1.9 \\
5.6 \\
6.2 \\
5.2\end{array}$ & $\begin{array}{l}10 \\
13 \\
14 \\
14 \\
27 \\
21 \\
14\end{array}$ & $\begin{array}{l}\text { liters } \\
.620 \\
.440 \\
.400 \\
.400 \\
.290 \\
.300 \\
.360\end{array}$ & $\begin{array}{l}\text { liters } \\
2.390 \\
2.300 \\
1.520 \\
1.300 \\
4.410 \\
2.470 \\
.810\end{array}$ \\
\hline
\end{tabular}
index decreases. Tidal volume is directly pro-

TABLE II

$m g$. When the mean mixing index of C. A. W. and J. G. are compared by the "t test" (Hall [14] p. 47) to evaluate the statistical significance of the difference between the two means, $t$ is found to equal 2.7 . For $n=5, P$ lies between 0.05 and 0.02 . This gives a highly significant $P$, and means that something other than common variance is responsible for the $P$ value, which is at the 5 per cent level of significance. The difference between $C$. A. W. and F.N.T. gives a $P$ which is not statistically significant and could easily be due to chance. 
portional to the mixing index. Neither of these correlations is particularly surprising, since a slow respiratory rhythm allows more time for mixing with each breath and a large tidal volume diminishes the waste inherent in a constant respiratory dead space. A fourth subject (F.N.T.) showed factor correlations with his mixing index similar to the normal individuals. He is not perceptibly disabled, and could be classified as a near-normal. The last three subjects, however, are moderately to severely incapacitated and the preceding correlations do not apply.

Normal subjects. The histories, physical examinations, and chest $\mathrm{x}$-rays of the two normal male subjects (C. A. W. and L. D. C.) revealed no pertinent abnormalities. Their lung volumes were almost identical with those predicted for their ages, sex and heights.

The third normal subject (S. M. N.), a healthy, 20-year-old female, had neither personal nor familial history of respiratory disease and was classified as normal by physical examination and x-ray. Nonetheless, her volume of residual air was unusually large, the $\mathrm{RA} / \mathrm{TLV} \times 100$ ratio being 37 per cent ( 17 per cent above the norm of her age group). This value, according to Baldwin and associates (13), would probably justify the diagnosis of "relative hyperinflation" or emphysema, yet her mixing efficiency as measured by the mixing index was the best of all the subjects in this study.

\section{Abnormal subjects}

F. N. T. is a 28-year-old male in whom an abnormality in the right lung field was discovered in his first $x$-ray taken in 1941 because of a severe upper respiratory tract infection (URI). Extended studies at a municipal tuberculosis clinic and elsewhere confirmed the diagnosis of congenital cystic disease. The patient was unaware of any disability before or after the diagnosis.

The fact that the amounts $(2,082$ and 1,800$)$ by which his measured TLV and VC fell below those predicted were nearly the same suggested that the cysts are predominantly closed. That a

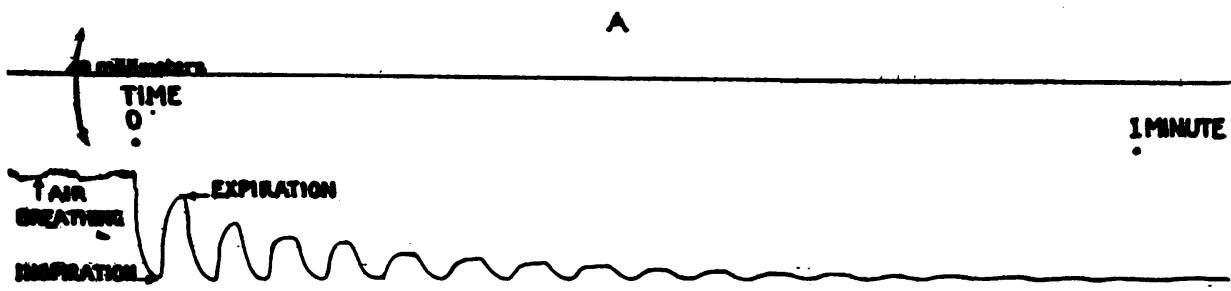

(FNT) $11-17-49$

B.

2 Minutes

C

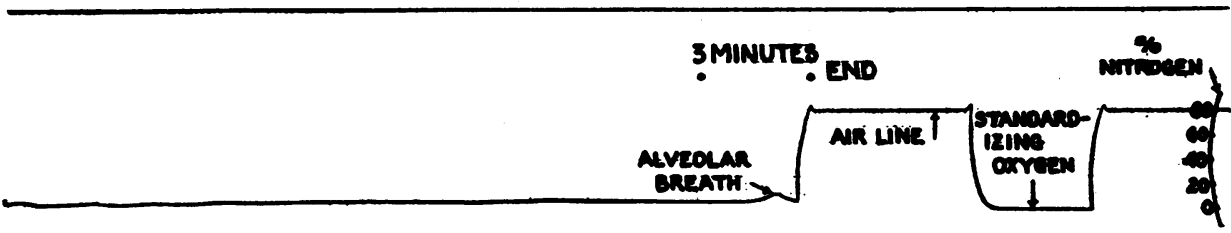

Fig. 2. The Changes in Nitrogen Concentration upon Rebreathing Oxygen : Subject F.N.T., Congenital Cystic Disease with UpPER Respiratory Infection

The upper channel in each of the three segments is used as a control line to detect tracking error. For further description see text. 
few cysts do communicate with the bronchi was demonstrated by maximal expirations shortly before equilibration. This patient cleared nitrogen from his lungs in the same time as the normal subjects, but on maximal expiration one-half minute before equilibration, he showed a 3 per cent increment in nitrogen concentration over the tidal concentration. Normal subjects showed only a .5 per cent increment at this time.

It is of interest that on one occasion (see Figure 2) when F. N. T. had a mild URI, he manifested the pattern of uneven or "cyclical" clearing, similar to that of the other pathological subjects. That is, on successive breaths the inspiratory-expiratory difference, instead of falling off smoothly and continuously to a straight line, repeatedly fell off progressively for a few breaths, only to increase slightly and then fall off again. The appearance of the cyclical pattern in this patient was suggestive of intermittent occlusion of a communicating cyst. A further abnormality was the 6 per cent increment in nitrogen concentration over tidal breathing upon a forced expiration after three minutes of rebreathing. Because the marked deviation of this tracing from his other tracings represented additional pathology, it was excluded from the analysis. In one normal subject (S.M.N.) with a similar URI at the time of testing, neither the cyclical pattern nor the post-equilibration alveolar nitrogen increment was observed.

J. M. I., a 41-year-old female, was a sanitorium patient at the time of this study. Her tuberculosis was discovered in 1932 when she applied for a health card, and treatment during her first admission consisted of a permanent left phrenicectomy. In 1937 a left extrapleural pneumothorax and oleothorax were performed. A diagnosis of bronchopleural fistula was made in 1944, but she did not consent to re-admission until 1946. At this time she was cyanotic at rest and had marked clubbing of the fingers. Subsequently, serial $\mathbf{x}$-rays showed a progressive clearing of the nodular disease in both lung fields and at the same time, the clubbing and cyanosis decreased.

The comparison of the measured TLV and VC and the predicted values for this patient resembled that for F. N. T.-i.e., the reduction was almost equal $(1,912$, and 1,748 , respectively). This indicates non-communicating and non-functioning lung tissue. In addition, the volume of residual air was somewhat enlarged relative to the TLV, giving a ratio of 41 per cent, which suggests mild emphysema. Her last test, taken six weeks after the first three tests, showed general improvement and therefore falsely magnified the statistical variability.

J. G., a 57-year-old-male, developed exertional dyspnea and recurrent hemoptysis in 1937. The only pertinent history was a ten-year period as a jack hammer operator. Beginning in 1942, he was followed at a municipal tuberculosis clinic, but a positive sputum was not obtained until 1948. At this time he was orthopneic and cyanotic. The AP diameter of the chest was markedly increased and a moderate dorsal kyphosis was present. An $x$-ray showed the typical picture of emphysema as well as some infiltration in both apices.

The data illustrate the classic findings of emphysema: 1) relatively normal TLV, 2) markedly reduced VC, 3 ) high ratio of RA to TLV (76 per cent), and 4), poor pulmonary mixing. J. G. was the most disabled patient in the series, and was the only one manifesting orthopnea and faint cyanosis at the time of testing.

M. W., is a 60 -year-old female with a history of lifelong, recurrent bronchitis and exertional dyspnea of two years' duration. X-ray showed slightly increased basal markings and slight generalized emphysema.

The data in this case are compatible with moderate emphysema. As in the previous subject ( $\mathrm{J}$. G.), the VC was markedly reduced, but TLV was normal. The ratio of RA to TLV was 51 per cent, and pulmonary mixing was low.

\section{DISCUSSION}

The reliability or reproducibility of a testing situation can be deduced from serial determinations in one (presumably constant) individual. In this study, reliability was measured by repeated testing at intervals ranging from one day to two-and-ahalf months.

In Table III the lung volume determinations are listed with their standard deviations. Unfortunately, complete comparison with other reports is impossible because 1) the older reports contain no statistical data, 2) the more recent reports do not present data uniformly, and 3) most reports, including this one, do not present samples large enough for meaningful comparison. Nonetheless, some roughly comparable data from other workers are cited here :

Open circuit method. Darling and colleagues (2) reported the range of five FRA determinations in 
TABLE III

\begin{tabular}{l|c|c|c|c|c|c|c|c|c|c|c}
\hline \hline & No. & FRA & S.D. & TLV & S.D. & Resid. & S.D. & $\begin{array}{c}\text { Comb. } \\
\text { VC }\end{array}$ & S.D. & Reserve & Compl. \\
\hline & & $c c$. & $c c$. & $c c$. & $c c$. & $c c$. & $c c$. & $c c$. & $c c$. & $c c$. & $c c$. \\
C. A. W. & 5 & 1,524 & \pm 77 & 5,528 & \pm 95 & 864 & \pm 124 & 4,664 & \pm 97 & 660 & 4,004 \\
L. D. C. & 5 & 2,304 & \pm 125 & 5,598 & \pm 121 & 1,432 & \pm 129 & 4,167 & \pm 130 & 872 & 3,294 \\
S. M. N. & 5 & 2,394 & \pm 247 & 4,648 & \pm 301 & 1,702 & \pm 234 & 2,946 & \pm 115 & 692 & 2,254 \\
F. N. T. & 5 & 1,296 & \pm 80 & 3,138 & \pm 132 & 768 & \pm 55 & 2,370 & \pm 11 & 530 & 1,842 \\
J. M. I. & 4 & 805 & \pm 74 & 1,628 & \pm 110 & 665 & \pm 70 & 962 & \pm 48 & 140 & 824 \\
J. G. & 3 & 4,410 & \pm 433 & 5,407 & \pm 421 & 4,100 & \pm 408 & 1,307 & \pm 93 & 310 & 997 \\
M. W. & 2 & 2,470 & \pm 156 & 3,880 & \pm 170 & 1,985 & \pm 276 & 1,895 & \pm 106 & 485 & 1,410 \\
\hline
\end{tabular}

$$
\text { S.D. }= \pm \sqrt{\frac{\sum \mathrm{d}^{2}}{\mathrm{~N}-1}} ; \text { Hall (14) p. } 6 .
$$

one normal as $160 \mathrm{cc}$; in three determinations on another normal the range was $305 \mathrm{cc}$. In the current series, the range in the five determinations on each of three normals was 190, 260 and 490 cc.

Constant volume closed circuit method. Herrald and McMichael (3) listed 42 duplicate determinations of FRA from a series of unselected male members of a mining population and obtained an over-all standard deviation of $259 \mathrm{cc}$. In our series, the standard deviations in the three normals were 77,125 , and $247 \mathrm{cc}$. The two emphysema cases (M. W. and J. G.) had standard deviations of 156 and $433 \mathrm{cc}$.

Constant volume closed circuit helium method. Meneely and Kaltreider (4) reported, on the basis of duplicate tests in 22 normal and 13 emphysematous patients, that 95 per cent of the FRA determinations should fall within 174 and $258 \mathrm{cc}$., respectively, of the mean or "true" values. More comparable to the current series were predominantly paired observations taken on different days in seven normal and two emphysematous subjects. From the 15 determinations in the normal subjects, an over-all standard deviation of $88 \mathrm{cc}$. can be derived. The corresponding figure from the five determinations in the two emphysema cases would be $134 \mathrm{cc}$. Thus, the variability of the lung volume determinations in this series compares favorably with that reported in other series where lung volume was determined from chemical analyses, accurate to the second decimal place. This contradiction is only suggestive of the fact that lung volume studies do not require the high degree of analytic accuracy previously recommended.

For clinical use, the chemical analyses for meter calibration may be obviated through the use of two tank mixtures (e.g., 15 and 30 per cent nitrogen in oxygen). This would make routine calibration prior to each test a simple procedure.

\section{SUMMARY}

1. A method of determining pulmonary capacity and function has been presented.

2. The method utilizes a conventional basal metabolism machine and an electronic nitrogen analyzer, simplifications designed to make the testing clinically feasible.

3. A new index of ventilatory efficiency, the "mixing index," is described, which takes into account variations in minute volume and lung size.

4. Data on three normal and four abnormal subjects are presented.

5. The testing variability by this method compares favorably with other series reported in the literature.

\section{ACKNOWLEDGMENT}

The authors wish to thank Stephen C. Mahady and Theodore C. Ruch for aid and encouragement in this study.

\section{BIBLIOGRAPHY}

1. Lassen, H. C. A., Cournand, A., and Richards, D. W., Jr., Distribution of respiratory gases in a closed breathing circuit. I. In normal subjects. J. Clin. Invest., 1937, 16, 1.

2. Darling, R. C., Cournand, A., and Richards, D. W., Jr., Studies on the intrapulmonary mixture of gases. III. An open circuit method for measuring residual air. J. Clin. Invest., 1940, 19, 609.

3. Herrald, F. J. C., and McMichael, J., Determination of lung volume: a simple constant volume modification of Christie's method. Proc. Roy. Soc., Series B, 1939, 126, 491. 
4. Meneely, G. R., and Kaltreider, N. L., Use of helium for determination of pulmonary capacity. Proc. Soc. Exper. Biol. \& Med., 1941, 46, 266.

5. Cournand, A., Darling, R. C., Mansfield, J. S., and Richards, D. W., Jr., Studies on the intrapulmonary mixture of gases. II. Analysis of the rebreathing method (closed circuit) for measuring residual air. J. Clin. Invest., 1940, 19, 599.

6. Christie, R. V., The lung volume and its subdivisions. I. Methods of measurement. J. Clin. Invest., 1932, 11, 1099.

7. Cournand, A., Baldwin, E. DeF., Darling, R. C., and Richards, D. W., Jr., Studies on intrapulmonary mixture of gases. IV. The significance of the pulmonary emptying rate and a simplified open circuit measurement of residual air. J. Clin. Invest., $1941,20,681$.

8. Boothby, W. M., Lundin, G., and Helmholz, H. F., Jr., A gaseous nitrogen elimination test to determine pulmonary efficiency. Proc. Soc. Exper. Biol. \& Med., 1948, 67, 558.

9. Lilly, J. C., and Anderson, T. F., The nitrogen meter: an instrument for continuously recording the concentration of nitrogen in gas mixtures. CAM Report No. 299, Washington, D. C., National Research Council, Division of Medical Sciences, 1944.

10. Lilly, J. C., Mixing of gases within respiratory system with a new type nitrogen meter. Am. J. Physiol., 1950, 161, 342.

11. Cournand, A., Yarmush, I. G., and Riley, R. L., Influence of body size on gaseous nitrogen elimination during high oxygen breathing. Proc. Soc. Exper. Biol. \& Med., 1941, 48, 280.

12. Darling, R. C., Cournand, A., Mansfield, J. S., and Richards, D. W., Jr., Studies on the intrapulmonary mixture of gases. I. Nitrogen elimination from blood and body tissues during high oxygen breathing. J. Clin. Invest., 1940, 19, 591.

13. Baldwin, E. DeF., Cournand, A., and Richards, D. W., Jr., Pulmonary insufficiency. I. Physiological classification, clinical methods of analysis, standard values in normal subjects. Medicine, 1948, 27, 243.

14. Hall, M. F., The Presentation of Medical Statistics. Overbeck Company, Ann Arbor, Michigan, 1946.

\title{
SPECIAL NOTICE TO SUBSCRIBERS
}

\author{
Post Offices will no longer forward the Journal \\ when you move.
}

Please notify Journal of Clinical Investigation, Business Office, c/o Cincinnati General Hospital, Cincinnati 29, Ohio, at once when you have a change of address and do not omit the zone number if there is one. 